\title{
Independent overexpression of the subunits of translation elongation factor complex eEF1H in human lung cancer
}

Maryna Veremieva', Liudmyla Kapustian', Antonina Khoruzhenko', Valery Zakharychev², Boris Negrutskii ${ }^{\text {* }}$ and Anna El'skaya ${ }^{1}$

\begin{abstract}
Background: The constituents of stable multiprotein complexes are known to dissociate from the complex to play independent regulatory roles. The components of translation elongation complex eEF1H (eEF1A, eEF1Ba, eEF1B eEF1BY) were found overexpressed in different cancers. To gain the knowledge about novel cancer-related translational mechanisms we intended to reveal whether eEF1H exists as a single unit or independent subunits in different human cancers.

Methods: The changes in the expression level of every subunit of eEF1H in the human non-small-cell lung cancer tissues were examined. The localization of eEF1H subunits was assessed by immunohistochemistry methods, subcellular fractionation and confocal microscopy. The possibility of the interaction between the subunits was estimated by co-immunoprecipitation.

Results: The level of eEF1B $\beta$ expression was increased more than two-fold in 36\%, eEF1By in 28\%, eEF1A in 20\% and $\mathrm{eEF} 1 \mathrm{Ba}$ in $8 \%$ of tumor specimens. The cancer-induced alterations in the subunits level were found to be uncoordinated, therefore the increase in the level of at least one subunit of eEF1H was observed in $52 \%$ of samples. Nuclear localization of eEF1Bß in the cancer rather than distal normal looking tissues was found. In cancer tissue, eEF1A and eEF1Ba were not found in nuclei while all four subunits of eEF1H demonstrated both cytoplasmic and nuclear appearance in the lung carcinoma cell line A549. Unexpectedly, in the A549 nuclear fraction eEF1A lost the ability to interact with the eEF1B complex.

Conclusions: The results suggest independent functioning of some fraction of the eEF1H subunits in human tumors. The absence of eEF1A and eEF1B interplay in nuclei of A549 cells is a first evidence for non-translational role of nuclear-localized subunits of eEF1B. We conclude the appearance of the individual eEF1B subunits in tumors is a more general phenomenon than appreciated before and thus is a novel signal of cancer-related changes in translation apparatus.
\end{abstract}

Keywords: Eukaryotic translation elongation factor 1, Macromolecular complexes, Protein biosynthesis, Lung cancer

\section{Background}

Living cells present a significant pool of proteins bound together in stable complexes to perform various biological functions. Forced dissociation of such complexes is important for response of the cell to some extracellular stimuli. Protein synthesis is one of the key milestones in

\footnotetext{
* Correspondence: negrutskii@imbg.org.ua

${ }^{1}$ State Key Laboratory of Molecular and Cellular Biology, Institute of Molecular Biology and Genetics NASU, 150 Acad.Zabolotnogo Str., Kiev 03680, Ukraine

Full list of author information is available at the end of the article
}

the process of realization of genetic information that includes a great variety of macromolecular complexes. Deregulation of translational control is a critical feature of carcinogenesis [1]. The involvement of translation initiation factors in the cancer progression has been studied extensively [2-5]. Although the elongation factors eEF1A and eEF2 are also involved in the abnormal translation program of cancer cells [6-8], there are very limited data on whether dissociation of the eEF1H complex is possible during the human cancer progression. 
The translation elongation complex eEF1H, comprising the eEF1A and eEF1B entities, is involved in the elongation phase of eukaryotic protein synthesis. eEF1A is responsible for the delivery of aminoacyl-tRNA to the A site of ribosome $[9,10]$. Eukaryotic eEF1B that consists of the scaffold $(\mathrm{eEF} 1 \mathrm{~B} \gamma)$ and two catalytic $(\mathrm{eEF} 1 \mathrm{~B} \alpha$ and $\mathrm{eEF} 1 \mathrm{~B} \beta)$ subunits, catalyzes GDP/GTP exchange in the eEF1A molecule [11]. Apart from their main role in translation, the eEF1H subunits have been reported to be involved in different processes unrelated to the translational apparatus. In particular, cancer-related overexpression of the eEF1B $\beta$ mRNA was found in lung cancer [12], medulloblastoma [13] and oesophageal carcinoma [14]. Up-regulation of the eEF1By was revealed in breast, colon, gastric and pancreatic tumors [15-18], whereas the eEF1B $\alpha$ was overexpressed in breast cancer [15]. It remains unclear if the cancer-induced overexpression of the eEF1B subunits is coordinated, or an increase of each subunit occurs independently.

Previously, we have analyzed the eEF1 subunits expression at mRNA and protein levels in the samples of human cardioesophageal and renal carcinomas $[19,20]$. The unbalanced expression of eEF1 subunits and the loss of integrity of the eEF1B complex have been observed in human cardioesophageal carcinoma rather than in renal cell carcinoma. That raises the question of whether the cardioesophageal carcinoma case is unique in relation to uncoupled changes in the levels of the eEF1B subunits, or the independent regulation of the subunits expression represents a more common situation in human cancer tissues.

Here, we performed a systematic analysis of the eEF1 subunits expression in 25 samples of human lung carcinoma. Uncoordinated elevation of the eEF1A, eEF1B $\beta$, $\mathrm{eEF} 1 \mathrm{~B} \gamma$ and, to some extent, eEF1B $\alpha$ subunits amount was found. An increase in the amount of at least one subunit of the eEF1 complex was found in $52 \%$ of the carcinoma specimens. The loss of the eEF1B integrity was confirmed by immunohistochemical analysis which demonstrated specific "cyto-nucleo" distribution of eEF1B $\beta$ in cancer tissue. We have also shown the presence of all eEF1H subunits and the absence of eEF1A-eEF1B interaction in the nuclei of lung adenocarcinoma A549 cells.

\section{Methods}

\section{Sample tissues}

Twenty-five primary tumor specimens and corresponding adjacent normal appearing tissue were obtained from 24 patients with NSCLC (19 adenocarcinomas and 5 squamous lung cell carcinomas) and 1 patient with SCLC during surgery at the Shupyk National Medical Academy of Postgraduate Education (Kiev, Ukraine). The ethical committee of the Institute of Molecular Biology and Genetics NASU (Kiev, Ukraine) has approved the project. All patients who participated in the study signed informed consent forms.
The tissue specimens were immediately immersed in liquid nitrogen and stored under the same conditions. The specimens of tumor and correspondingly paired distal normal appearing tissues were used for mRNA and protein isolation. For immunohistochemistry analysis, the tissue samples were fixed in 10\% buffered formalin for $48 \mathrm{~h}$.

\section{Plasmids and antibodies}

The plasmids with eEF1A1, eEF1A2, eEF1B $\alpha$, eEF1B $\beta$ and eEF1By cDNAs inserts were kindly provided by C.R. Knudsen, Aarhus University, Denmark, G.M. Janssen, Leiden University, the Netherlands, V.F. Shalak, Institute of Molecular Biology and Genetics NASU, Kiev, Ukraine. The following primary antibodies have been used in experiments: mouse anti-eEF1A (Millipore, USA); in-house mouse anti-eEF1B $\alpha$, anti-eEF1B $\beta$ and rabbit anti-eEF1B $\gamma$ [20]; mouse anti-eEF1B $\alpha$, anti-eEF1B $\beta$ and mouse antieEF1B $\gamma$ (Abnova, Taiwan); mouse anti- $\beta$-actin, (Santa Cruz Biotechnology, USA), rabbit anti-PARP (Cell Signaling, USA), rabbit anti-histone $\mathrm{H} 3.3$ and mouse anti- $\beta$-Tubulin (Millipore, USA). Immunoblot signals were obtained after incubation with secondary antibodies conjugated with horseradish peroxidase using Immobilon Western Chemiluminescent HRP Substrate (Millipore, USA). Immunofluoresent detection was done with TRITIC - conjugated anti-mouse IgG secondary antibodies (Millipore, USA).

\section{Northern blot analysis}

Total RNA was isolated from frozen tissues using TRI Reagent (Sigma, St Louis, MO, USA). The RNA (10 $\mu$ g per lane) was electrophoretically separated in $1 \%$ agarose gel containing 2.2 $\mathrm{M}$ formaldehyde and then transferred to the Nytran Nylon $\mathrm{N}$ membrane (Whatman, Maidstone, Kent, UK). Northern blot has been performed as described earlier [19]. To determine whether the eEF1 mRNAs could be up- or down-regulated during carcinogenesis, the $\beta$ actin mRNA was used as a reference. No marked tendency of the overall increase or decrease in the actin mRNA level in the lung carcinoma samples was revealed when compared to normal samples.

\section{Western blot analysis}

The frozen tissue specimens were homogenized in the presence of liquid nitrogen in a lysis buffer $(10 \mathrm{mM}$ $\mathrm{K}_{2} \mathrm{HPO}_{4}, 100 \mathrm{mM} \mathrm{NaCl}, 1 \% \mathrm{NP}-40,1 \mathrm{mM}$ DTT, $0.1 \mathrm{mM}$ PMSF, pH 7.4), incubated in an ice bath for $30 \mathrm{~min}$ and centrifuged at $13000 \mathrm{~g}$ for $20 \mathrm{~min}$ at $4^{\circ} \mathrm{C}$. The protein concentration in the supernatants was determined by the Bradford method [21]. Immunoblotting has been done as described previously [19]. Endogenous $\beta$-actin was used as a loading control. The densitometry analysis of signals was performed by the Scion Image program. The target protein expression was evaluated using the relative intensity ratio of target protein/loading control. 
More than twofold alterations of the mRNA and protein amount in the tumor samples when compared to the normal ones were taken as a meaningful difference.

\section{Cell fractionation}

A549 cells were cultured in DMEM (Sigma, USA) growth medium with 10\% FBS (Sigma, USA) and 1\% penicillin/streptomycin (Sigma). Cells were grown up to $7 \times 10^{6}$ cells $/ \mathrm{ml}$ and harvested with Trypsin-EDTA. Nuclear fraction was obtained as described in [22] with modifications. Cells were resuspended in 1,5 volume of lysis buffer (10 mM HEPES pH7.9, $1.5 \mathrm{mM} \mathrm{MgCl}_{2}, 0.5 \%$ NP-40, $0.2 \mathrm{mM}$ PMSF, $0.5 \mathrm{mM}$ DTT) and incubated on ice for $20 \mathrm{~min}$. Suspended cells were centrifuged at $400 \mathrm{~g}$ for $10 \mathrm{~min}$ following with supernatant centrifugation at $16000 \mathrm{~g}$ for $30 \mathrm{~min}$. Obtained fraction was used as cytoplasmic extract. Pellet after low speed centrifugation was resuspended in 4,5 volumes of sucrose buffer (10 mM HEPES, $0.25 \mathrm{mM}$ sucrose, $1.5 \mathrm{mM} \mathrm{MgCl}_{2}$, $10 \mathrm{mM} \mathrm{KCl}, 0.1 \%$ NP-40, 0.5 mM DTT, $0.2 \mathrm{mM} \mathrm{PMSF)}$ and incubated on ice for $10 \mathrm{~min}$. Suspension was loaded on sucrose cushion (2 $\mathrm{M}$ sucrose) and centrifuged at $400 \mathrm{~g}$ for $10 \mathrm{~min}$. After upper buffer and bottom sucrose were discarded, nuclei were resuspended in lysis buffer and centrifuged at $1500 \mathrm{~g}$ for $10 \mathrm{~min}$. Procedure was repeated twice. Nuclear pellet was resuspended in $1 / 2$ of starting cell volume of nuclear lysis buffer $(20 \mathrm{mM}$ HEPES pH 7.9, 25\% glycerol, $0.42 \mathrm{M} \mathrm{NaCl}, 1.5 \mathrm{mM}$ $\mathrm{MgCl}_{2}, 0.2 \mathrm{mM}$ DTT, $0.2 \mathrm{mM}$ EDTA, $0.2 \mathrm{mM} \mathrm{PMSF}$ ), incubated on ice for $30 \mathrm{~min}$ and centrifuged at $16000 \mathrm{~g}$ for $30 \mathrm{~min}$. Obtained fraction was used as source of nuclear protein.
The quality of cytoplasmic and nuclear fractions was analyzed by Western blot with primary rabbit anti-PARP, rabbit anti-Histone 3.3 (nuclear markers) and mouse anti-Tubulin (cytoplasmic marker) antibodies.

\section{Immunoprecipitation}

Cytoplasmic and nuclear extracts from A549 cells were incubated with Protein G Sepharose (Sigma, USA) for 1 hour at $4^{\circ} \mathrm{C}$. Rabbit anti-eEF1B $\gamma$ antibodies $(1.5 \mu \mathrm{g}$ of antibodies per $1 \mathrm{mg}$ of total protein) were added to pre-cleared lysates and the incubation persisted for 2 hours at $4^{\circ} \mathrm{C}$. To precipitate the antibody-protein complex, Protein G Sepharose was added according to the manufacturer's protocol and incubated for 1 hour at $4^{\circ} \mathrm{C}$. To control non-specific binding with Protein G Sepharose, pre-cleared lysate was incubated with the beads only during 1 hour at $4^{\circ} \mathrm{C}$. All incubations have been done with orbital shaker. The samples were analyzed by Western blot.

\section{Immunohistochemistry and immunofluorescence analysis} Cultured A549 cells were fixed with methanol for 5 min at room temperature. Thereafter, the cells were permeabilized with $0.2 \%$ Triton X 100 in PBS for 15 min. Non-specific binding was blocked after incubation with Ultra Vision Protein Block buffer (Thermo Scientific, USA) for $5 \mathrm{~min}$. Anti-eEF1By antibodies were applied at dilution 1:100 in PBS with $1 \% \mathrm{BSA}$ for 1 hour at $37^{\circ} \mathrm{C}$. The secondary TRITC conjugated anti-mouse antibodies were applied in dilution 1:100 (Millipore, USA). Cell nuclei were counterstained with Hoechst 33258. Samples were washed and embedded into Mowiol medium (Sigma). Microscopy study

\section{$\frac{1}{N T} \frac{2}{N T} \frac{3}{N T} \frac{4}{N T} \frac{5}{N T} \frac{6}{N T} \frac{7}{N T} \frac{8}{N T} \frac{9}{N T} \frac{10}{N T} \frac{11}{N T} \frac{12}{N T} \frac{13}{N T} \frac{14}{N T} \frac{15}{N T} \frac{16}{N T} \frac{17}{N T}$
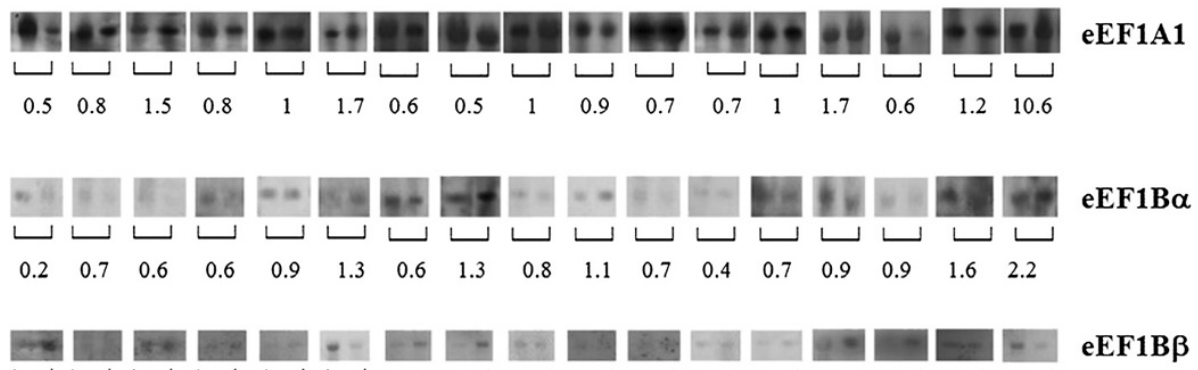

Figure 1 Comparison of the level of mRNAs coding for different subunits of eEF1H in human lung carcinoma and normal lung Representative Northern blots are shown. N - normal issue, T - tumor tissue. Molecular size: eEF1A1 mRNA 3500 bp, eEF1Ba mRNA 850 bp, eEF1Bß mRNA 1300 bp, eEF1By mRNA 1500 bp, $\beta$-actin mRNA 1800 bp. Numeration of samples is according to Table 1. 
was performed using Zeiss LSM 510 META confocal laser scanner microscope (Carl Zeiss, Jena, Germany).

Immunostaining of tissue sections was performed as described earlier [19].

\section{Results}

Expression of the mRNAs coding for eEF1H subunits in the human lung carcinoma tissue

The expression of mRNAs coding for eEF1A1, eEF1B $\alpha$, eEF1B $\beta$ and eEF1B $\gamma$ in human lung cancer was assessed by Northern blot analysis of 25 clinical tumor specimens. A representative experiment is shown in Figure 1. Analysis of the expression of mRNA coding for the individual eEF1H subunits has shown overexpression of eEF1B $\beta$ mRNA (32\% of cases) and eEF1By mRNA ( $24 \%$ of cases) in cancerous samples (Table 1). The expression of mRNA coding for the putative oncogenic isoform eEF1A2 was not detected by Northern blot (data not shown).
Expression of protein entities of the eEF1 complex in the human lung carcinoma tissue

The protein content of eEF1 subunits was examined in the same tumor samples by Western blot analysis. A representative experiment is shown in Figure 2. Independent $\geq 2$-fold overexpression of at least one eEF1 component was detected in $52 \%$ of all tumor specimens (Table 1). A substantial cancer-related elevation was observed for the eEF1B $\beta$ (36\%) and eEF1By (28\%) subunits. We did not observe any significant changes in the eEF1B $\alpha$ protein level. In fact, eEF1B $\alpha$ increased $\geq 2$-fold only in two clinical samples out of 25 .

Importantly, the unbalanced changes in the eEF1H subunits content were observed in the vast majority of the tumor samples (Table 1). No cancer-induced changes in the expression level of any subunit were found in three patients (the patients' numbers $4,7,16$ ). $\geq 2$-fold overexpression of all $\mathrm{eEF} 1 \mathrm{H}$ subunits at protein level in concert was found only in one case (specimen number 5 ). The coordinated increase in the protein amount of

Table 1 Changes in the expression levels of the eEF1H mRNAs and corresponding proteins in human lung tumours

\begin{tabular}{|c|c|c|c|c|c|c|c|c|c|c|}
\hline \multirow[t]{3}{*}{ № } & \multirow[t]{3}{*}{ Stage } & \multirow[t]{3}{*}{ Diagnose } & \multicolumn{8}{|c|}{ Fold expression, tumor/normal tissues } \\
\hline & & & \multicolumn{2}{|c|}{ eEF1A } & \multicolumn{2}{|c|}{ eEF1Ba } & \multicolumn{2}{|c|}{ eEF1B $\beta$} & \multicolumn{2}{|c|}{ eEF1By } \\
\hline & & & mRNA & Protein & mRNA & Protein & mRNA & Protein & mRNA & Protein \\
\hline 1 & I & SCLC & 0.5 & 0.7 & 0.2 & 0.9 & 6.4 & 1 & 0.4 & 1.2 \\
\hline 2 & $\|$ & Adenocarcinoma & 0.8 & 1.6 & 0.7 & 1.3 & 0.9 & 1 & 4.8 & 2 \\
\hline 3 & III & Squamous lung cell carcinoma & 1.5 & 1 & 0.6 & 1 & 0.4 & 1.2 & 0.2 & 0.8 \\
\hline 4 & III & Adenocarcinoma & 0.8 & 1.7 & 0.6 & 1.2 & 0.9 & 1 & 1.2 & 1.9 \\
\hline 5 & । & Adenocarcinoma & 1 & 3.2 & 0.9 & 2.6 & 1.2 & 2.6 & 0.3 & 2.8 \\
\hline 6 & $\|$ & Adenocarcinoma & 1.7 & 1.7 & 1.3 & 0.9 & 0.5 & 4 & 1.5 & 2.3 \\
\hline 7 & $\|$ & Squamous lung cell carcinoma & 0.6 & 0.9 & 0.6 & 1 & 1.8 & 1.2 & 0.8 & 0.9 \\
\hline 8 & $\|$ & Adenocarcinoma & 0.5 & 1.4 & 1.3 & 1 & 0.7 & 2.5 & 0.4 & 0.7 \\
\hline 9 & $\|$ & Adenocarcinoma & 1 & 1.5 & 0.8 & 1 & 1.6 & 3 & 4 & 0.8 \\
\hline 10 & $\|$ & Adenocarcinoma & 0.9 & 2 & 1.6 & 1.2 & 1.1 & 2 & 5.5 & 2.6 \\
\hline 11 & $\|$ & Adenocarcinoma & 0.7 & 1.2 & 0.7 & 1 & 1.3 & 0.8 & 0.5 & 0.6 \\
\hline 12 & $\|$ & Adenocarcinoma & 0.7 & 1.4 & 0.4 & 0.7 & 2.6 & 0.7 & 1 & 0.9 \\
\hline 13 & $\|$ & Adenocarcinoma & 1 & 2.3 & 0.7 & 1.1 & 1.4 & 1.8 & 1.1 & 1.4 \\
\hline 14 & । & Adenocarcinoma & 1.7 & 1.1 & 0.9 & 1.6 & 8 & 1.2 & 1.2 & 1.8 \\
\hline 15 & $\|$ & Squamous lung cell carcinoma & 0.6 & 1.6 & 0.9 & 0.9 & 2.2 & 1.5 & 0.8 & 0.3 \\
\hline 16 & $\|$ & Adenocarcinoma & 1.2 & 0.9 & 1.6 & 1.3 & 1.1 & 1.3 & 1.6 & 0.9 \\
\hline 17 & $\|$ & Squamous lung cell carcinoma & 10.6 & 1.6 & 2.2 & 3 & 0.2 & 1.2 & 2 & 0.9 \\
\hline 18 & $\|$ & Adenocarcinoma & 1 & 2 & 0.9 & 1.4 & 1.3 & 2.4 & 1.7 & 1.5 \\
\hline 19 & $\|$ & Adenocarcinoma & 0.9 & 1.8 & 1 & 1.4 & 2.2 & 2 & 6 & 2.3 \\
\hline 20 & III & Adenocarcinoma & 3.3 & 0.7 & 2.9 & 1.3 & 4.3 & 0.6 & 11 & 0.6 \\
\hline 21 & $\|$ & Adenocarcinoma & 0.6 & 2.1 & 0.8 & 1.3 & 3.2 & 2.2 & 1.2 & 1.3 \\
\hline 22 & III & Adenocarcinoma & 0.8 & 0.6 & 0.4 & 1.5 & 0.2 & 1.1 & 1.6 & 0.5 \\
\hline 23 & III & Squamous lung cell carcinoma & 0.7 & 1.4 & 1.5 & 1.3 & 2 & 2.3 & 0.8 & 2.3 \\
\hline 24 & $\|$ & Adenocarcinoma & 0.6 & 0.7 & 0.5 & 0.9 & 1.4 & 0.3 & 0.7 & 17 \\
\hline 25 & I & Adenocarcinoma & 1.1 & 0.8 & 0.2 & 1.2 & 0.9 & 0.5 & 1 & 0.7 \\
\hline
\end{tabular}




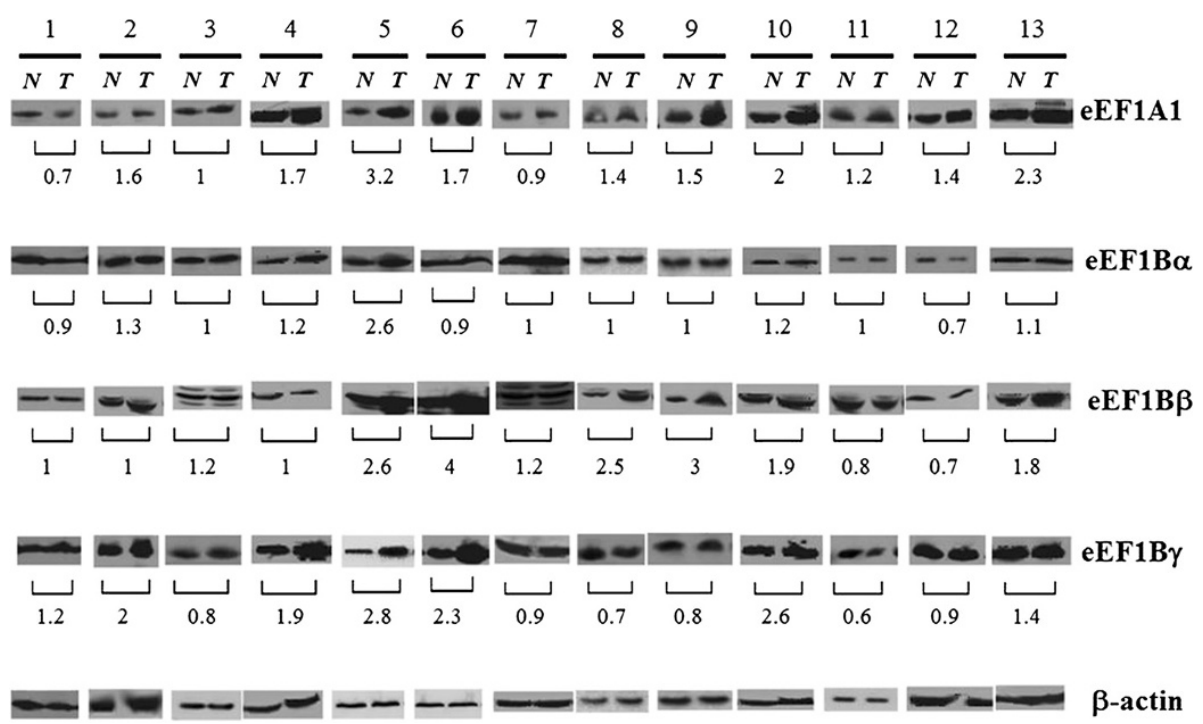

Figure 2 Comparison of the level of different subunits of eEF1H in human lung carcinoma and normal lung. Representative Western blots are shown. $\mathrm{N}$ - normal tissue, $\mathrm{T}$ - tumor tissue. Molecular weights: eEF1A $\sim 50 \mathrm{kDa}$, eEF1Ba $28 \mathrm{kDa}$, eEF1B $\sim 35 \mathrm{kDa}$, eEF1BY $\sim 51 \mathrm{kDa}$, $\beta$-actin $\sim 42 \mathrm{kDa}$. Numeration of samples is according to Table 1.

eEF1B $\beta$ and eEF1B $\gamma$ was noticed in 5 clinical samples (patients' numbers $5,6,10,19,23$ ), i.e. $71 \%$ of the specimens, where the overexpression of eEF1By was found. The correlation between overexpression of mRNAs coding for different subunits and the corresponding proteins was observed in nearly half of the tumor specimens where the mRNA overexpression was detected.

\section{Nuclear localization of eEF1 components in human lung} Previously, we have observed different locations of the individual eEF1B subunits in the human cardioesophageal carcinoma samples by immunohistochemical analysis [19]. To examine whether the eEF1B subunits demonstrate cancer-related re-localization in human lung cancer the histochemical analysis was performed with the lung cancer samples. Strong staining of all target proteins was detected in both normal and cancerous epithelial cells (Figure 3). Perinuclear appearance of eEF1A and eEF1B $\alpha$ was observed in the cells of normal and cancerous lung tissues. eEF1B $\beta$ was detected in perinuclear region of normal cells while in the cancerous tissue eEF1B $\beta$ showed both cytoplasmic and nuclear localization. eEF1B $\gamma$ was found in cell nuclei and cytoplasm in the normal and cancerous lung tissues (Figure 3). One may speculate that the simultaneous presence of eEF1B $\beta$ and eEF1B $\gamma$ in the cancer cell nuclei may be a tumor-related sign of a suggested previously binary eEF1B $\beta-\mathrm{eEF} 1 \mathrm{~B} \gamma$ complex, which could be formed de novo or be a remnant of eEF1H.

To analyze nuclear localization of the eEF1B $\beta$ and eEF1By subunits in more detail, we isolated the fraction of nuclear proteins from the human lung adenocarcinoma cell line A549. Unexpectedly, all eEF1H subunits were found to be present in both cytoplasmic and nuclear fractions of A549 cells (Figure 4A) which contradicted the data on the cancer tissues where eEF1A and $\mathrm{eEF} 1 \mathrm{~B} \alpha$ were not found in nucleus. The nucleuslocated eEF1A and eEF1B $\alpha$ did not seem to be contaminants from outer side of nuclear membrane, as these subunits were not present in the nuclear membrane fraction of A549 cells (Figure 4A). eEF1B $\gamma$ was found in all subcellular fractions including the nuclear membrane fraction, indicating the possibility of cross-contamination of the fractions with eEF1By. Therefore, a confocal microscopy of A549 cells was conducted to specify intracellular localization of eEF1By. As seen in Figure 4B, the eEF1By subunit was present in both cytoplasm and nucleus of A549 cells. Thus, in the lung cancer cell line all subunits of eEF1B demonstrate both cytoplasmic and nuclear localization.

The question remains whether the nucleus-localized subunits of eEF1B can interact with each other in A549 cells. Since $\mathrm{eEF} 1 \mathrm{~B} \gamma$ is believed to serve as a core subunit for the eEF1B complex, we used anti-eEF1B $\gamma$ antibodies to co-precipitate the eEF1B $\alpha$ and $e E F 1 B \beta$ subunits from both cytoplasmic and nuclear fractions of the A549 cell line (Figure 4C). Co-precipitation of all eEF1B subunits in the nuclear extract was revealed, suggesting that the eEF1B complex may be present in the nucleus. Unexpectedly, in the nuclear fraction of A549 cells the interaction of the eEF1B complex with eEF1A was not detected despite eEF1A being present in the nuclear fraction. Contrary to that, the eEF1A-eEF1B interaction was observed in the cytoplasmic extract (Figure 4C). 

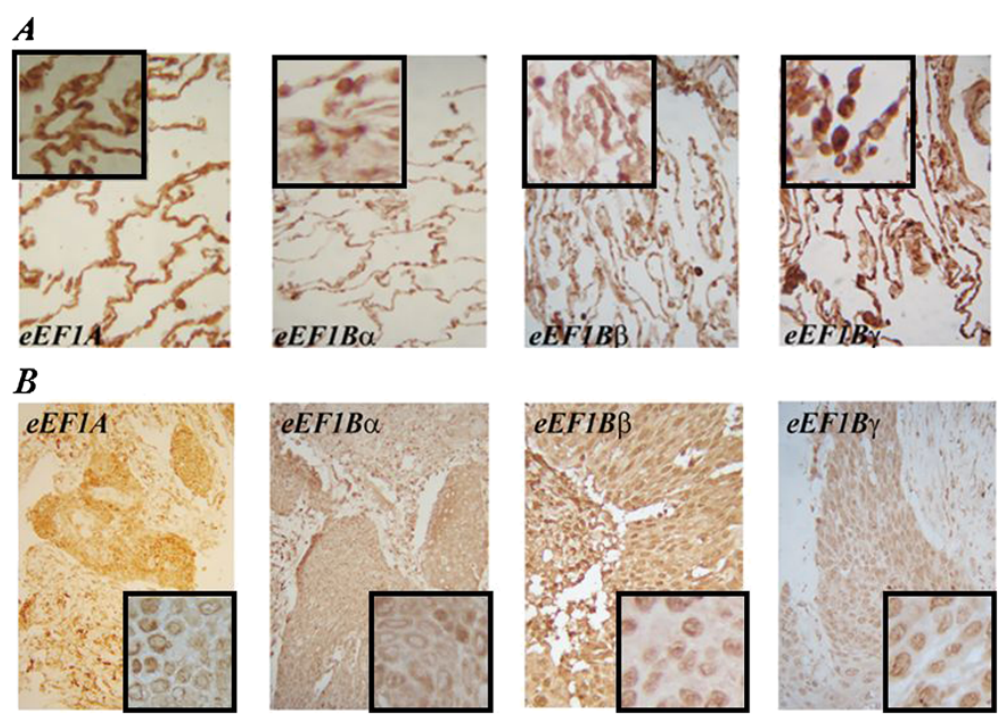

Figure $3 \mathbf{~ I m m u n o h i s t o c h e m i c a l ~ a n a l y s i s ~ o f ~ t h e ~ e E F 1 H ~ s u b u n i t s ~ i n ~ h u m a n ~ l u n g ~ c a r c i n o m a . ~ ( A ) ~ N o r m a l ~ t i s s u e , ~ ( B ) ~ C a n c e r o u s ~ t i s s u e . ~}$ The sample 24 (Table 1) was used for analysis. Magnification is 20x, insert - 100x.

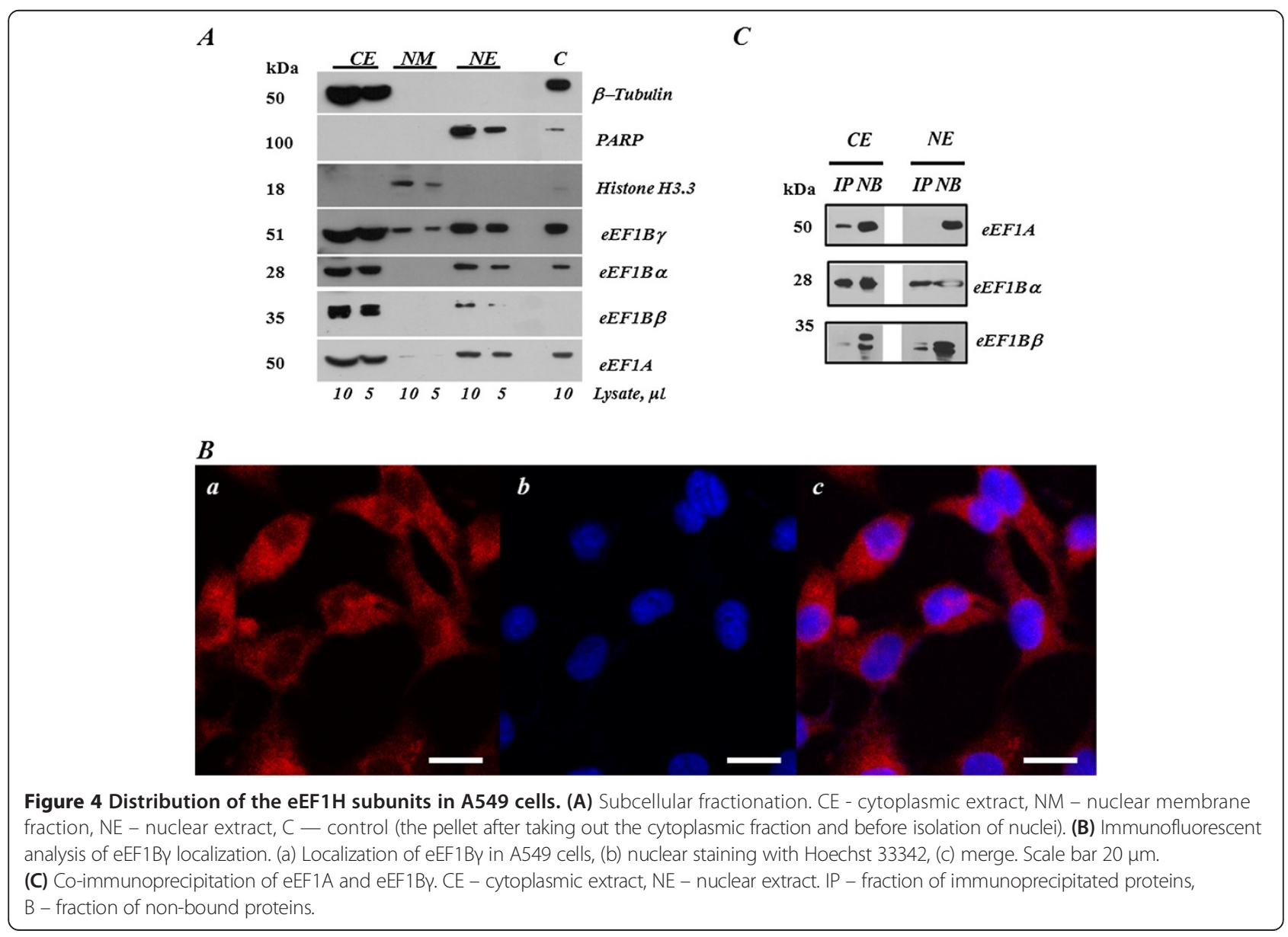




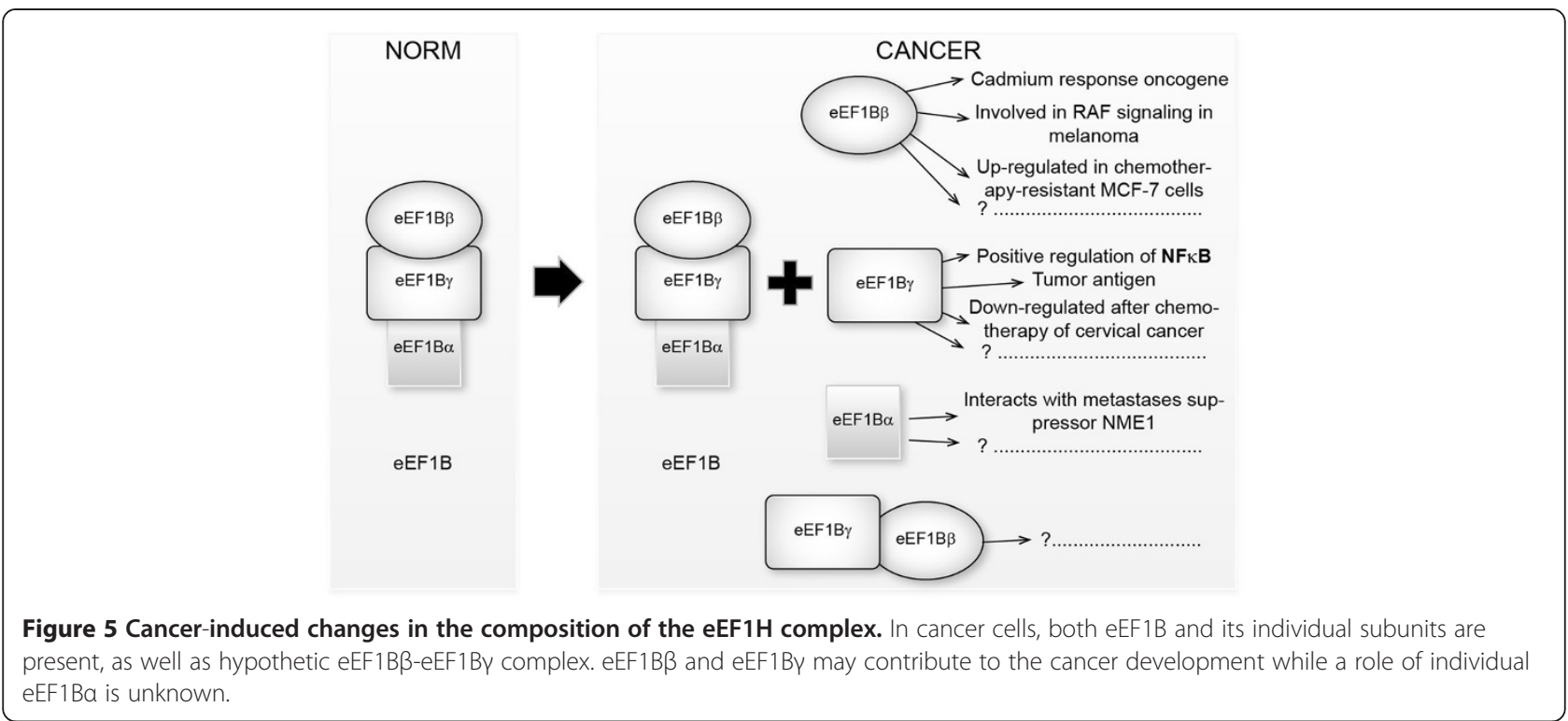

\section{Discussion}

The lack of correlated changes in the expression level of all $\mathrm{eEF} 1 \mathrm{H}$ subunits suggests the presence of the individual, non-complexed subunits of eEF1H in lung cancer tissue. Oncogenic properties of eEF1B $\beta$ were described earlier [23]. In particular, overexpression of eEF1B $\beta$ inhibits E3 ubiquitin ligase SIAH- 1, the enzyme which can suppress tumor development via targeting of oncogenic and anti-apoptotic proteins $[24,25]$. The role of individual $\mathrm{eEF} 1 \mathrm{~B} \gamma$ in cancer is not so clear. This subunit is a participant of oxidative stress response pathway. In the absence of eEF1By this pathway is constitutively active [26], thus, overexpression of individual eEF1By in tumor cells may impair cellular ROS detoxification, which sensitizes tumor cells to ROS-induced cell death. Recently, it has been shown that eEF1B $\gamma$, being phosphorylated at Ser294 by DOA protein kinase, down-regulates transport of several classes of membrane organelles, including peroxisomes and mitochondria, along microtubules [27]. An effect of this phosphorylation on the ability of eEF1BY to be in complex with other subunits of eEF1B remains to be investigated. Recently, ectopically expressed individual eEF1By was shown to interact with $\mathrm{NFK}_{\mathrm{K}} \mathrm{B}$ and positively regulate NFkB-mediated signal cascades [28]. NFkB is known factor of cancer-related inflammation which is widely involved in the initiation and progression of cancer.

The functions of a protein may depend on whether or not this protein is present in a cell as a single entity or as a component of high-molecular weight complex [29]. Our hypothesis is that the eEF1B complex functions in the same way both in tumor and in normal tissues, providing nascent polypeptide elongation process with the GTPbound form of eEF1A while free subunits of eEF1B are directed towards fulfillment of different cancer-related duties (Figure 5).

It is noteworthy that more than 2-fold elevation of eEF1B $\beta$ protein in the cancer tissues relative to the control has occurred in $71 \%$ of the specimens which demonstrate the eEF1By overexpression (Table 2). Similar coordinated increase of eEF1B $\beta$ and eEF1B $\gamma$ subunits content was observed previously in human cardioesophageal carcinoma [19]. Parallel increase in the eEF1B $\beta$ and eEF1By amount in cancer tissues hints that these subunits of eEF1B may act together under cancer conditions. eEF1B $\beta$ plays a role as a guanine exchange factor, while eEF1BY may serve as an anchoring unit for eEF1B $\beta$, providing specific subcellular localization of the latter. Importantly, the literature data suggest that both $\operatorname{eEF} 1 \mathrm{~B} \beta$ and eEF1B $\gamma$ possess pro-tumor properties [30-35] while eEF1B $\alpha$ does not (Figure 5).

Subcellular localization of the eEF1H subunits was investigated in the lung cancer tissue samples and cell line. All eEF1H subunits were found in nuclei of A549

Table 2 Overexpression of eEF1H subunits at protein level in different human cancer tissues

\begin{tabular}{lccc}
\hline eEF1 & \multicolumn{3}{c}{ \% of cases } \\
\cline { 2 - 4 } subunit & $\begin{array}{l}\text { Cardioesophageal } \\
\text { carcinoma [19] }\end{array}$ & $\begin{array}{l}\text { Lung } \\
\text { carcinoma }\end{array}$ & $\begin{array}{l}\text { Renal } \\
\text { carcinoma [20] }\end{array}$ \\
\hline eEF1A & 36 & 20 & 5 \\
eEF1Ba & 20 & 8 & 0 \\
eEF1Bß & 36 & 36 & 5 \\
eEF1By & 36 & 28 & 5 \\
All subunits & 72 & 52 & 16 \\
\hline
\end{tabular}


cells (Figure 4A), whereas the only eEF1By and eEF1B $\beta$ nuclear localization was found in the lung cancer specimens by immunohistochemical investigation (Figure 3). This difference may be patient-specific or represent a genuine divergence in the eEF1B localization between cultivating cells and cancer tissues. More importantly, the immunoprecipitation analysis did not reveal the classic eEF1H complex in nucleus, as the eEF1A-eEF1B interaction was not detected there despite the presence of all factors in the nuclear fraction. Molecular reasons for this are under investigation and may be related to a different level of post-translational modifications of the eEF1A or eEF1B components. Notably, the phosphorylation of eEF1B $\beta$ can influence its interaction with eEF1A [36]. A reason for the presence of the eEF1H subunits in nucleus is unknown. The data on the existence of nuclear protein synthesis remain controversial [36-43]. As eEF1A and eEF1B did not interact in the nuclear fraction of the cancer cells, this argues against nuclear translation and suggests independent roles of eEF1A and eEF1B. eEF1B was reported to participate in the cell cycle events [44], interact with NFkB [28], play an essential role in the oxidative stress response pathway $[26,45]$, contribute to cytoskeleton rearrangements [46] and proteolytic system [47].

The analysis of data described here and in [19] uncovered an interesting trend related to overexpression of the eEF1H subunits in different human cancers (Table 2). Cardioesophageal and lung carcinomas showed increased level of expression of all eEF1H subunits observed in $8-36 \%$ of all samples, depending on the subunit and tumour type. However, as the changes in the subunits expression are not coordinated, the elevated protein levels of one or another subunit expression were found in $72 \%$ of cardioesophageal [19] and 52\% of lung carcinomas. Interestingly, we did not observe marked difference in the eEF1H proteins expression in human kidney tumours [20] where the overexpression of the eEF1A and eEF1By proteins was found in two diverse tumour samples out from eighteen specimens researched. This finding favours the specificity of the phenomenon and suggests that the combined increase of different eEF1B subunits of the eEF1H complex may be considered as useful addition to the panel of markers for lung and cardioesophageal carcinomas.

\section{Conclusions}

Taken together, our data revealed that structurally and functionally independent existence of the subunits of the translation elongation complex eEF1B in tumour tissues may be a widespread, albeit specific phenomenon. This finding provides new insights into understanding of principles of the organization of translation apparatus in cancer cells and contributes to the panel of potential markers for lung and cardioesophageal carcinomas.

\section{Abbreviations}

eEF1H: "heavy" form of translation elongation factors complex; eEF1A: subunit A of eEF1H; eEF1B: sub-complex of eEF1H which consists from eEF1Ba, eEF1B $\beta$ and eEF1By subunits; SCLC: small cell lung carcinoma.

\section{Competing interests}

The authors declare that they have no competing interests.

\section{Authors' contributions}

MV performed experimental research on mRNA, protein expression, cell fractionation and immunoprecipitation, LK performed experiments on cell fractionation and immunofluorescence, AK participated in immunohistochemical analysis, VZ collected and analysed tissue specimens, BN designed the study and wrote manuscript, AE wrote and edited the manuscript. All authors read and approved the final manuscript.

\section{Acknowledgements}

We thank O. Koroliov for participation in the studies and K. Albert for editing of the manuscript.

Research was partially supported by funds from France-Ukraine PICS and GDRI programs.

\section{Author details}

${ }^{1}$ State Key Laboratory of Molecular and Cellular Biology, Institute of Molecular Biology and Genetics NASU, 150 Acad.Zabolotnogo Str., Kiev 03680, Ukraine. ${ }^{2}$ Shupyk National Medical Academy of Postgraduate Education, 9 Dorohozhyts'ka str., Kiev 04112, Ukraine.

Received: 1 July 2014 Accepted: 25 November 2014

Published: 3 December 2014

\section{References}

1. Stumpf CR, Ruggero D: The cancerous translation apparatus. Curr Opin Genet Dev 2011, 21(4):474-483.

2. Robert F, Pelletier J: Translation initiation: a critical signalling node in cancer. Expert Opin Ther Targets 2009, 13(11):1279-1293.

3. Rosenwald IB, Hutzler MJ, Wang S, Savas L, Fraire AE: Expression of eukaryotic translation initiation factors $4 \mathrm{E}$ and 2alpha is increased frequently in bronchioloalveolar but not in squamous cell carcinomas of the lung. Cancer 2001, 92:2164-2171.

4. Brass N, Heckel D, Sahin U, Pfreundschuh M, Sybrecht GW, Meese E: Translation initiation factor elF-4gamma is encoded by an amplified gene and induces an immune response in squamous cell lung carcinoma. Hum Mol Genet 1997, 6:33-39.

5. Bauer C, Brass N, Diesinger I, Kayser K, Grasser FA, Meese E: Overexpression of the eukaryotic translation initiation factor 4G (elF4G-1) in squamous cell lung carcinoma. Int J Cancer 2002, 98:181-185.

6. Vislovukh A, Kratassiouk G, Porto E, Gralievska N, Beldiman C, Pinna G El'skaya A, Harel-Bellan A, Negrutskii B, Groisman I: Proto-oncogenic isoform $A 2$ of eukaryotic elongation factor eEF1 is a target of miR-663 and miR-744. Br J Cancer 2013, 108(11):2304-2311.

7. Joseph P, O'Kernick CM, Othumpangat S, Lei YX, Yuan BZ, Ong TM: Expression profile of eukaryotic translation factors in human cancer tissues and cell lines. Mol Carcinog 2004, 40(3):171-179.

8. Oji Y, Tatsumi N, Fukuda M, Nakatsuka S, Aoyagi S, Hirata E, Nanchi I, Fujik F, Nakajima H, Yamamoto Y, Shibata S, Nakamura M, Hasegawa K, Takagi S, Fukuda I, Hoshikawa T, Murakami Y, Mori M, Inoue M, Naka T, Tomonaga T, Shimizu Y, Nakagawa M, Hasegawa J, Nezu R, Inohara H, Izumoto S, Nonomura N, Yoshimine T, Okumura M, et al:: The translation elongation factor eEF2 is a novel tumor-associated antigen overexpressed in various types of cancers. Int J Oncol 2014, 44(5):1461-1469.

9. Lukash TO, Turkivska HV, Negrutskii BS, El'skaya AV: Chaperone-like activity of mammalian elongation factor eEF1A: renaturation of aminoacyl-tRNA synthetases. Int J Biochem Cell Biol 2004, 36(7):1341-1347.

10. Kanibolotsky DS, Novosyl'na OV, Abbott CM, Negrutskii BS, El'skaya AV: Multiple molecular dynamics simulation of the isoforms of human translation elongation factor $1 \mathrm{~A}$ reveals reversible fluctuations between "open" and "closed" conformations and suggests specific for eEF1A1 affinity for Ca2+-calmodulin. BMC Struct Bio/ 2008, 8:4

11. Andersen GR, Nissen $P$, Nyborg J: Elongation factors in protein biosynthesis. Trends Biochem Sci 2003, 28(8):434-441. 
12. Liu Y, Chen Q, Zhang JT: Tumor suppressor gene 14-3-3sigma is down-regulated whereas the proto-oncogene translation elongation factor 1delta is up-regulated in non-small cell lung cancers as identified by proteomic profiling. J Proteome Res 2004, 3(4):728-735.

13. De Bortoli M, Castellino RC, Lu XY, Deyo J, Sturla LM, Adesina AM, Perlaky L, Pomeroy SL, Lau CC, Man TK, Rao PH, Kim JY: Medulloblastoma outcome is adversely assotiated with overexpression of EEF1D, RPL30, and RPS20 on the long arm of chromosome 8. BMC Cancer 2006, 6:223.

14. Ogawa K, Utsunomiya T, Mimori K, Tanaka Y, Tanaka F, Inoue H, Murayama S, Mori M: Clinical significance of elongation factor-1 delta mRNA expression in oesophageal carcinoma. Br J Cancer 2004, 91:282-286.

15. Al-Maghrebi M, Anim JT, Olalu AA: Up-regulation of eukaryotic elongation factor-1 subunits in breast carcinoma. Anticancer Res 2005, 25:2573-2577.

16. Chi $\mathrm{K}$, Jones DV, Frazier ML: Expression of an elongation factor 1 gamma-related sequence in adenocarcinomas of the colon. Gastroenterology 1992, 103:98-102.

17. Mimori K, Mori M, Tanaka S, Akiyoshi T, Sugimachi K: The overexpression of elongation factor 1 gamma mRNA in gastric carcinoma. Cancer 1995, 75(Suppl. 6):1446-1449.

18. Lew $Y$, Jones DV, Mars WM, Evans D, Byrd D, Frazier ML: Expression of elongation factor-1 gamma-related sequence in human pancreatic cancer. Pancreas 1992, 7:144-152.

19. Veremieva M, Khoruzhenko A, Zaicev S, Negrutskii B, El'skaya A: Unbalanced expression of the translation complex eEF1 subunits in human cardioesophageal carcinoma. Eur J Clin Investig 2011, 41:269-276.

20. Veremieva MV, Zgonnik YM, Negrutskii BS, El'skaya AV: Expression of the subunits of multiprotein translation elongation complex eEF1H in human renal carcinomas. Biopolym Cell 2011, 27:279-284.

21. Bradford $M: A$ rapid and sensitive method for the quantitation of microgram quantities of protein utilizing the principle of protein-dye binding. Anal Biochem 1976, 72:248-254.

22. Dignam JD, Lebovitz RM, Roeder RG: Accurate transcription initiation by RNA polymerase II in a soluble extract from isolated mammalian nuclei. Nucleic Acids Res 1983, 11(5):1475-1489.

23. Joseph $P$, Lei YX, Ong TM: Up-regulation of expression of translation factors-a novel molecular mechanism for cadmium carcinogenesis. Mol Cell Biochem 2004, 255(1-2):93-101.

24. Matsuzawa SI, Reed JC: Siah-1, SIP, and Ebi collaborate in a novel pathway for beta-catenin degradation linked to $\mathrm{p} 53$ responses. Mol Cell 2001, 7(5):915-926.

25. Yoshibayashi H, Okabe H, Satoh S, Hida K, Kawashima K, Hamasu S, Nomura A, Hasegawa S, Ikai I, Sakai Y: SIAH1 causes growth arrest and apoptosis in hepatoma cells through beta-catenin degradationdependent and -independent mechanisms. Oncol Rep 2007, 17(3):549-556.

26. Esposito AM, Kinzy TG: The eukaryotic translation elongation Factor 1Bgamma has a non-guanine nucleotide exchange factor role in protein metabolism. J Biol Chem 2010, 285(49):37995-38004.

27. Serpinskaya AS, Tuphile K, Rabinow L, Gelfand VI: Protein kinase Darkener of apricot and its substrate EF1 $y$ regulate organelle transport along microtubules. J Cell Sci 2014, 127(Pt 1):33-39.

28. Liu D, Sheng C, Gao S, Jiang W, Li J, Yao C, Chen H, Wu J, Chen S, Huang W: $\mathrm{eEF} 1 \mathrm{~B} Y$ is a positive regulator of NF-KB signaling pathway. Biochem Biophys Res Commun 2014, 446(2):523-528.

29. Ray PS, Arif A, Fox PL: Macromolecular complexes as depots to releasable regulatory proteins. Trends Biochem Sci 2007, 32(4):158-164.

30. Joseph P, Lei YX, Whong WZ, Ong TM: Oncogenic potential of mouse translation elongation factor-1 delta, a novel cadmium-responsive proto-oncogene. J Biol Chem 2002, 277(8):6131-6136.

31. Old WM, Shabb JB, Houel S, Wang H, Couts KL, Yen CY, Litman ES, Croy CH, Meyer-Arendt K, Miranda JG, Brown RA, Witze ES, Schweppe RE, Resing KA, Ahn NG: Functional proteomics identifies targets of phosphorylation by B-Raf signaling in melanoma. Mol Cell 2009, 34(1):115-131.

32. Lu Q, Lei $Y X$, He CC, Lei ZN: Blood translation elongation factor-1 $\delta$ is a novel marker for cadmium exposure. Int J Mol Sci 2013, 14(3):5182-5197.

33. Chen $L$, Chen W, Zhao L, Yu HZ, Li X: Immunoscreening of urinary bladder cancer CDNA library and identification of potential tumor antigen. World J Urol 2009, 27(1):107-112.

34. Liu H, Han Y, Mi R, Zhang Y, Su G, Wang H, Zhou X, Liu X, Zhu B: Identification of cervical cancer proteins associated with treatment with paclitaxel and cisplatin in patients. Int J Gynecol Cancer 2011, 21(8):1452-1457.
35. Zheng G, Peng F, Ding R, Yu Y, Ouyang $Y$, Chen Z, Xiao Z, He Z: Identification of proteins responsible for the multiple drug resistance in 5-fluorouracil-induced breast cancer cell using proteomics analysis. J Cancer Res Clin Oncol 2010, 136(10):1477-1488.

36. Sivan G, Aviner R, Elroy-Stein O: Mitotic modulation of translation elongation factor 1 leads to hindered tRNA delivery to ribosomes. J Biol Chem 2011, 286:27927-27935.

37. Nathanson L, Xia T, Deutscher MP: Nuclear protein synthesis: a re-evaluation. RNA 2003, 9(1):9-13.

38. Belgrader $\mathrm{P}$, Cheng J, Maquat LE: Evidence to implicate translation by ribosomes in the mechanism by which nonsense codons reduce the nuclear level of human triosephosphate isomerase mRNA. Proc Natl Acad Sci U S A 1993, 90(2):482-486.

39. Birnstiel ML, Flamm WG: Intranuclear site of histone synthesis. Science 1964, 145(3639):1435-1437.

40. Iborra FJ, Jackson DA, Cook PR: Coupled transcription and translation within nuclei of mammalian cells. Science 2001, 293(5532):1139-1142.

41. Bohnsack MT, Regener K, Schwappach B, Saffrich R, Paraskeva E, Hartmann E, Görlich D: Exp5 exports eEF1A via tRNA from nuclei and synergizes with other transport pathways to confine translation to the cytoplasm. EMBO J 2002, 21(22):6205-6215.

42. Dahlberg JE, Lund E: Does protein synthesis occur in the nucleus? Curr Opin Cell Biol 2004, 16(3):335-338.

43. David A, Dolan BP, Hickman HD, Knowlton JJ, Clavarino G, Pierre P, Bennink JR, Yewdell JW: Nuclear translation visualized by ribosome-bound nascent chain puromycylation. J Cell Biol 2012, 197(1):45-57.

44. Boulben S, Monnier A, Le Breton M, Morales J, Cormier P, Belle R, Mulner-Lorillon O: Sea urchin elongation factor 1delta (EF1delta) and evidence for cell cycle-directed localization changes of a sub-fraction of the protein at M phase. Cell Mol Life Sci 2003, 60:2178-2188.

45. Olarewaju O, Ortiz PA, Chowdhury WQ, Chatterjee I, Kinzy TG: The translation elongation factor eEF1B plays a role in the oxidative stress response pathway. RNA Biol 2004, 1:89-94.

46. Kim S, Kellner J, Lee CH, Coulombe PA: Interaction between the keratin cytoskeleton and eEF1Bgamma affects protein synthesis in epithelial cells. Nat Struct Mol Biol 2007, 14:982-983.

47. Wu H, Shi Y, Lin Y, Qian W, Yu Y, Huo K: Eukaryotic translation elongation factor 1 delta inhibits the ubiquitin ligase activity of SIAH-1. Mol Cell Biochem 2011, 357(1-2):209-215.

doi:10.1186/1471-2407-14-913

Cite this article as: Veremieva et al:: Independent overexpression of the subunits of translation elongation factor complex eEF1H in human lung cancer. BMC Cancer 2014 14:913.

\section{Submit your next manuscript to BioMed Central and take full advantage of:}

- Convenient online submission

- Thorough peer review

- No space constraints or color figure charges

- Immediate publication on acceptance

- Inclusion in PubMed, CAS, Scopus and Google Scholar

- Research which is freely available for redistribution 